\title{
Pacing Postconditioning: Recent Insights of Mechanism of Action and Probable Future Clinical Application
}

\author{
Fawzi A. Babiker \\ Department of Physiology, Faculty of Medicine, Health Sciences Center, Kuwait University, Kuwait City, Kuwait
}

\author{
Key Words \\ Ischemia reperfusion - Postconditioning . \\ Pacing postconditioning
}

\begin{abstract}
Ischemic heart disease, also known as coronary heart disease or coronary artery disease, accounts for $>50 \%$ of cardiovascular events and is a leading cause worldwide of morbidity and mortality. Hypoperfusion of the heart is the major cause of injury in ischemic heart disease, as it results in the death of cardiomyoctes due to a lack of oxygen and energy. This injury ultimately leads to a dead area in the heart called infarcted area or myocardial infarction. The formation of myocardial infarction leads to a lengthy process of remodeling which causes many changes in the architecture and the electrophysiology of the heart. These changes may eventually lead to death due to arrhythmia or heart failure. Tremendous efforts have been made over the last decades to decrease the burden of ischemic reperfusion (I/R) injury. The first salvage to the ischemic heart is reperfusion; however, this procedure is associated with a subsequent reperfusion injury. In the 1980s, a method known as preconditioning was introduced and showed great potential in combating ischemic heart disease, but this technique is limited by the difficulty
\end{abstract}

of its translation to the clinic as it requires the anticipation of an occurrence of ischemic heart disease. Not long after, a new method, postconditioning, was introduced. This method showed great success, and several studies were performed to investigate its signaling cascades and the possibility of its translation to the clinic. Thereafter, several trials were made, and many methods of postconditioning were developed. One of these is intermittent dyssynchrony, pacing postconditioning (PPC), of the heart, which involves brief episodes of electrical pacing. PPC afforded a pronounced protection to the heart against I/R injury, similar to that afforded by pre- and postconditioning. @ $2015 \mathrm{~S}$. Karger AG, Basel

\section{Introduction}

Despite all the efforts made to decrease cardiovascular morbidity and mortality, ischemic heart disease still accounts for some of the high mortality rates [1]. After continuous efforts to decrease the mortality related to ischemic injury, researchers and clinicians were able to introduce a vitally important technique, reperfusion. They managed to open the occluded coronary artery and restore the blood supply to the affected part of the heart.

\begin{tabular}{ll}
\hline KARGER & $\begin{array}{l}\text { () 2015 S. Karger AG, Basel } \\
1011-7571 / 15 / 0257-0022 \$ 39.50 / 0 \quad \text { Karger }\end{array}$ \\
$\begin{array}{l}\text { E-Mail karger@karger.com } \\
\text { www.karger.com/mpp }\end{array}$ & $\begin{array}{l}\text { This is an Open Access article licensed under the terms of the } \\
\text { Creative Commons Attribution-NonCommercial 3.0 Un- } \\
\text { ported license (CC BY-NC) (www.karger.com/OA-license), } \\
\text { applicable to the online version of the article only. Distribu- } \\
\text { tion permitted for non-commercial purposes only. }\end{array}$
\end{tabular}

Dr. Fawzi A. Babiker

Department of Physiology, Faculty of Medicine

Kuwait University, PO Box 249233

Safat 13110 (Kuwait)

E-Mail Fawzi.b@hsc.edu.kw 
This procedure contributed notably to decreasing the morbidity and mortality associated with ischemic heart disease [2]. However, this method of protection contributes its own injury, which is caused by the sudden reperfusion and oxygenation to the affected tissue $[3,4]$. This injury is mainly a result of myocardial stunning, microvascular and endothelial injury and irreversible cell damage or necrosis $[3,5]$. Although reperfusion remained the gold standard treatment for ischemic injury for some time, the search for a reasonable remedy for both ischemia and reperfusion damage continued for several years before a viable solution was obtained. In the past, manipulating the heart by conditioning showed encouraging results, which suggested that it may be a promising procedure for reducing ischemic reperfusion (I/R) injury in the near future [6]. Many methods of intervention evolved and were proposed as vital tools for decreasing I/R injury [7]. Conditioning the heart can be executed at several time points related to the time of occurrence of the I/R and can be achieved by various methods. The first method introduced was ischemic preconditioning, which is a protective method by which a brief ischemia before the major prolonged ischemia protected the heart against the subsequent lethal ischemic injury [8]. The support afforded by this method of conditioning was believed to be evoked by a brief interruption of the blood flow to the insulted area. Preconditioning afforded remarkable protection to the hearts of patients undergoing percutaneous coronary intervention [9]. Equally, this intervention was proven to be very effective in heart transplantation and open chest surgery. However, although there were numerous procedures and methods of preconditioning, it was restricted to very narrow events because of the lack of predictability of an ischemic attack in healthy individuals. This situation necessitated the search for a potent procedure that could afford optimum protection from I/R injury to the heart. Benefiting from the knowledge and experience gained in preconditioning research, Zhao et al. [10] introduced another method of conditioning lately known as ischemic postconditioning. This method involved a repetitive ischemia at the beginning of the reperfusion that followed prolonged ischemic injury. This procedure of conditioning gained enormous publicity because of its execution at reperfusion, which gave it a great chance of translation to the clinic [10]. Interestingly, this method of protection can be mimicked by drugs either before the ischemic insult (pharmacological preconditioning) or after the insult (pharmacological postconditioning) [11, 12]. Indeed, great success was achieved in the protection of the heart

Future of Pacing Postconditioning in the Clinic by this postconditioning, but its application on the affected blood vessel raised great concern which hindered its utilization in the clinic [13]. As an alternative method of avoiding the affected blood vessel, a potent intervention exploiting the same idea of pre- and postconditioning was introduced. This intervention was done on an organ or vascular bed remote from the affected blood vessel or tissue targeting the protection of the insulted organs and was accordingly called remote pre- or postconditioning, respectively $[14,15]$. Recently, the group of Prinzen [16] introduced intermittent dyssynchrony, pacing postconditioning (PPC), induced by ventricular pacing to the heart, which causes a local change in the load of the ventricle. The mechanism of this protection seems to act by decreasing the stretch at the site of pacing and increasing it at a site remote from it [16]. This change in the ventricular load is believed to be the trigger of the protection PPC affords to the heart. Like all other scenarios of conditioning, PPC afforded an evident protection to the heart when applied before ischemia or at the beginning of reperfusion [17]. Both prepacing conditioning and PPC result in a protection of the myocardium similar to that attained by other methods of conditioning [18].

\section{Conditioning as a Strategy for Heart Protection}

To target ischemic injury, reperfusion is the most effective intervention, and its ultimate injury can be antagonized by postconditioning [10]. Combining reperfusion and postconditioning further decreases I/R injury; however, it does not eliminate it completely. Since the introduction of postconditioning, many studies have been done on animals and in the clinic [10, 19, 20]. Quite excellent achievements were attained in the animal and small clinical studies; however, the results of the largest clinical studies were disappointing $[21,22]$ (table 1). Similarly, many of the drugs used to target I/R injury showed positive results in animals and small clinical studies [23], but their use in large clinical studies gave a disappointing outcome [24] (table 1). Some other methods of protection were executed during ischemia, such as remote pre- and postconditioning; however, the failure of the large-scale trial also compromised their translation to the clinic [25, 26]. Surprisingly, to date there is no drug which has been proven to afford optimum protection to the heart or to make outstanding progress in the protection of the heart against I/R injury (table 1). PPC is done 'remotely' from the occluded blood vessel; however, on the same organ, it 
could be a promising method of protection of the heart. Interestingly, PPC can be performed at reperfusion or simultaneously during ischemia to decrease ischemic injury and completely abrogate the reperfusion injury. This review focused on PPC to the heart, as it has the potential of in the future being a leading method in the protection of the heart against I/R injury in the clinical setting.

\section{PPC: The New Potentials of Protection}

In PPC, myocardial protection was proven to be triggered by brief periods of intermittent mechanical dyssynchrony induced by ventricular pacing at normal heart rate during the early moments of reperfusion [17]. Pacing preconditioning was induced by 3 episodes of 5-min duration of left ventricular pacing interspersed with 3 episodes of 5 -min right atrium pacing prior to the index ischemia. In 2006, Vanagt et al. [16] reported a reduction in the myocardial infarct size by brief periods of PPC for the first time. Based on their findings, in 2007 the same group investigated the possibility of protection if the same protocol of pacing preconditioning was applied at reperfusion [17]. They used isolated rabbit hearts which were subjected to 30 -min regional ischemia followed by 3 cycles of 5 -min left ventricular pacing alternated with 3 cycles of 5-min right atrium pacing [17]. This study reported a significant reduction in the infarct size comparable to that produced by pacing preconditioning [17]. Interestingly, PPC was translated successfully to rat and pig hearts after its success in the rabbit $[18,27]$. The protection of PPC was attained in isolated, buffer-perfused as well as blood-perfused hearts in vivo [18]. It is worth noting that the infarct size reduction by PPC was proven to be sustained over the long term. The abnormal mechanical loading of the myocardium is believed to be the trigger of this PPC-induced protection [18]. These findings were also supported by another study which proved the protection of the myocardium by mechanical stretch [28]. Stretch was also proven to be effective in the protection of the heart as shown by Gysembergh et al. [29]. Previous studies have shown that myocardial blood flow or lactate release did not change during the switching from the right atrium to left ventricular pacing in the early reperfusion phase of PPC [16, 17]. This finding provides solid proof that ischemia and graded reperfusion are not likely to be triggers of PPC protection [18]. The notion that the abnormal stretch of the myocytes leads to a release of angiotensin, which is known to induce a hypertrophic response in the myo-
Table 1. Clinical trials with remote preconditioning, pharmacological conditioning, preconditioning and postconditioning that did not show protection of the heart against I/R injury

Treatment methods

Remote preconditioning

Lavi et al. [26], 2014

Rentoukas et al. [49], 2010

Karuppasamy et al. [50], 2011

Carrasco-Chinchilla et al. [25], 2013

Pavione et al. [51], 2012

Lucchinetti et al. [52], 2012

Rahman et al. [53], 2010

Hong et al. [54], 2010

Li et al. [55], 2010

Munk et al. [56], 2010

Pharmacological conditioning

Landoni et al. [47], 2008

Bates et al. [57], 2008

Liem et al. [58], 2009

Desmet et al. [59], 2011

Kitakaze et al. [60], 2007

Ott [61], 2010

Najjar et al. [62], 2011

Ross et al. [46], 2005

Fokkema et al. [63], 2009

Preconditioning

Ghosh et al. [64], 2003

Wu et al. [65], 2001

Cremer et al. [66], 1997

Postconditioning

Limalanathan et al. [22], 2014

Freixa et al. [21], 2012

Sorensson et al. [67], 2010

cyte, had not been validated in the previous PPC studies. Our recent studies did not show a role for angiotensin II in the protection of the heart by PPC. The angiotensin receptor 1 blocker candesartan does not affect the protective role of PPC, which excludes angiotensin receptor 1 as a candidate in PPC-induced protection [18]. This suggests the presence of intermediate candidates that might be important in the upstream protective pathways of PPC.

The downstream pathways of PPC resemble those of the ischemic pre- and postconditioning, but its upstream pathways showed a clear variation (fig. 1). It was shown that protein kinase $\mathrm{C}$ activation, which is important in ischemic postconditioning, is involved in PPC protection 


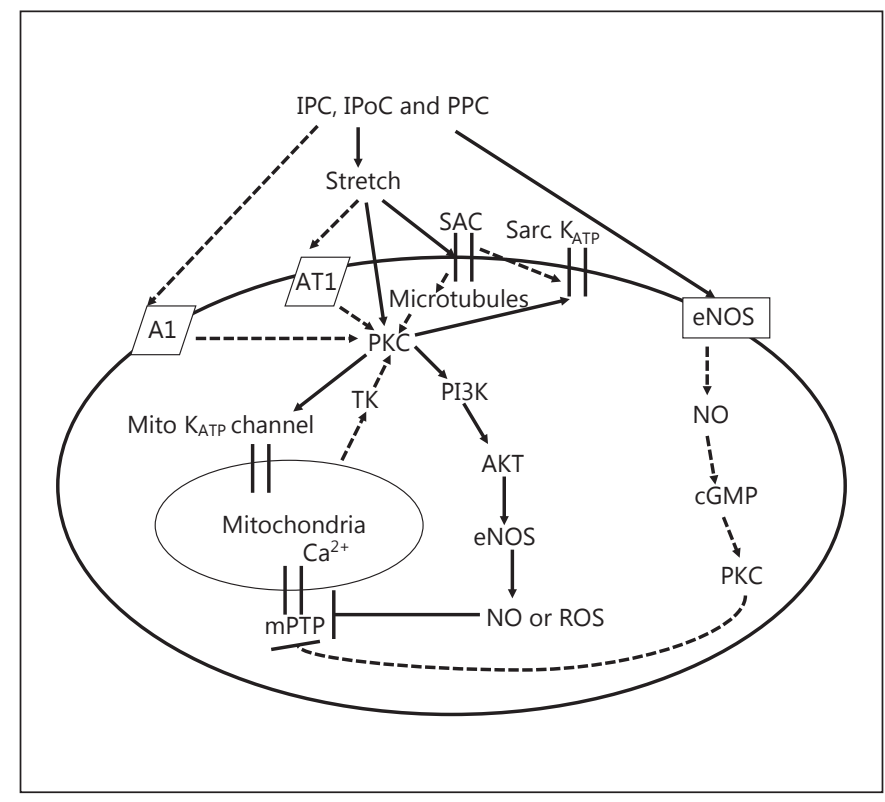

Fig. 1. Schematic representation showing the potential pathways for preconditioning, postconditioning and PPC. The dashed lines show pathways which are not known in PPC protection. A1 = Adenosine receptor 1 ; AKT = protein kinase $\mathrm{B}$; At1 = angiotensin receptor 1 ; cGMP = cyclic guanosine monophosphate; eNOS = endothelial nitric oxide synthase; IPC = ischemic postconditioning; $\mathrm{IPoC}=$ ischemic postconditioning; Mito $\mathrm{K}_{\mathrm{ATP}}=$ mitochondrial ATP-sensitive $\mathrm{K}^{+}$channel; $\mathrm{mPTP}=$ mitochondria permeability transition pore; $\mathrm{NO}=$ nitric oxide; $\mathrm{PKC}=$ protein kinase $\mathrm{C}$; ROS = reactive oxygen species; $\mathrm{SAC}=$ stretch activated channel; Sarc $\mathrm{K}_{\mathrm{ATP}}=$ sarcolemmal ATP-sensitive $\mathrm{K}^{+}$channel; $\mathrm{TK}=$ tyrosine kinase.

[18]. Another important pathway of PI3K-Akt, which is also referred to as RISK pathway [18, 30, 31], was proven to be effective in PPC [18]. Furthermore, the blockade of the mitochondrial ATP-sensitive $\mathrm{K}^{+}$channel by 5-hydroxydecanoate eliminates the cardioprotective effect of PPC [18]. Accordingly, the opening of the mitochondrial ATP-sensitive $\mathrm{K}^{+}$channel is considered to be an important candidate in the cardioprotection mediated by PPC (fig. 1). To attain the optimum beneficial effects, PPC should be applied during the first 5 min of reperfusion. It can be applied clinically in heart transplants, cardiac surgery and percutaneous coronary intervention [18]. Recently, a role for tumor necrosis factor $\alpha$, brain natriuretic peptide and nitric oxide in PPC was reported by Babiker et al. [27]. PPC, however, was proven not to be effective in diabetic animals, but it was similarly effective in male and female hearts with no remarkable gender differences [32]. Microtubules were also proven to be involved in the protection afforded by PPC [18].

Future of Pacing Postconditioning in the Clinic

\section{Future of Heart Protection and PPC}

Despite the success of all the methods of conditioning in animal studies, the translation to the clinic is rather limited and compromised by the lack of an optimum protective effect. Recently, the negative results reported by three big trials in ischemia and remote conditioning have caused an obstacle for the future of conditioning research. Ischemic preconditioning was proven to be effective in salvaging the heart [8], but its translation to the clinic was limited by the lack of a predictable time of occurrence of the ischemic insult [33]. However, it is still beneficial in patients undergoing percutaneous coronary intervention or opening side branch occlusion $[34,35]$. Indeed, both preconditioning and postconditioning techniques accommodate the risk of injury as they are applied on the occluded blood vessel $[36,37]$. In contrast, remote preand postconditioning are done with no risk away from the insulted organ with promising results in the protection of the heart. Preconditioning done on the same vascular bed [15], on a remote vascular bed in a remote organ [38] or in small clinical trials $[39,40]$ showed a considerable protection. Unfortunately, the translation of this method to the clinic is jeopardized by the unpredictable occurrence of ischemia. Postconditioning that can be applied after the onset of ischemia at the beginning of reperfusion afforded effective and successful protection to the heart in animals [10] and humans [20]. Remote postconditioning was applied to avoid the anticipated injury of the blood vessels. A strong body of evidence has shown that remote postconditioning is effective in animal studies $[41,42]$ and in ST elevation myocardial infarction [14, 43]. Recently, this method of protection has been put on hold because of the disappointing results of the last few large-scale studies $[25,26]$ (table 1). The use of the drugs in preconditioning and postconditioning $[44,45]$ protection showed great success in animals and small clinical experiments [23], but the application in large experiments did not produce the required optimum protection $[24,46]$ (table 1). Furthermore, the protective effects of anesthetics shown in animal studies did not show the required protection in the clinic [47]. To date, PPC seems to be the best candidate for the application in the clinic. Interestingly, however, not applied directly to the heart, recurrent electroconvulsive therapy did not impose harmful effects on the heart [48]. PPC is applied on the same organ away from any capillary bed, and it is void of the vascular damage of the other methods [18]. PPC can be performed during the occlusion (sustained ischemia). It has the potential of being applied as precondition-

Med Princ Pract 2016;25(suppl 1):22-28 
ing before starting reperfusion or as a postconditioning method at the onset of reperfusion. Interestingly, preconditioning pacing and PPC can easily be combined to produce additive protection, which may be beneficial for the protection of diabetic and hypertrophied hearts.

The only important limitation of PPC is its invasive nature. This shortcoming can be extenuated by the fact that invasion is unavoidable in the treatment of ischemia as the catheter will be inserted anyway in order to open the occlusion or to place the stent. Interestingly, the same catheter can be used for pacing the heart. Furthermore, the PPC technique is easy and inexpensive and can be applied in ordinary clinical settings.

\section{Conclusion}

PPC is one of the various methods of postconditioning. It implies an abnormal stretch of the heart induced by electrical pacing in the protection of the heart against $\mathrm{I} / \mathrm{R}$ injury. It is applied remotely from the affected coronary artery; however, it is applied on the same organ.
While it shares the downstream pathways of protection with the other postconditioning methods, its downstream pathways are different. These characteristics give it potential for adding to the protection gained by other methods of protection. Furthermore, being easy and safe to apply suggests it as a future method for the protection of the heart; however, its beneficial effects are to be confirmed beforehand by pilot studies on the human heart.

\section{Acknowledgments}

Part of this work was done at the laboratories of Dr. Frits Prinzen, Department of Physiology, Maastricht University, The Netherlands and of Dr. Fawzi Babiker, Department of Physiology, Kuwait University. Part of this work was supported by the Kuwait University research grants No. MY03/10 and 02/10. The author would like to thank Dr. Azuwuike Owunwanne and Dr. Suleiman $\mathrm{Al}$ Sabah for reading and commenting on this paper.

\section{Disclosure Statement}

The author has no conflicts of interest to reveal.

\section{References}

1 Roger VL, Go AS, Lloyd-Jones DM, et al: Heart disease and stroke statistics - 2011 update: a report from the American Heart Association. Circulation 2011;123:e18-e209.

2 Steg PG, James SK, Atar D, et al: Task Force on the management of ST-segment elevation acute myocardial infarction of the European Society of Cardiology (ESC): ESC guidelines for the management of acute myocardial infarction in patients presenting with ST-segment elevation. Eur Heart J 2012;33:25692619.

3 Yellon DM, Baxter GF: Protecting the ischaemic and reperfused myocardium in acute myocardial infarction: distant dream or near reality? Heart 2000;83:381-387.

4 Yellon DM, Hausenloy DJ: Myocardial reperfusion injury. N Engl J Med 2007;357:11211135.

5 Ambrosio G, Tritto I: Reperfusion injury: experimental evidence and clinical implications. Am Heart J 1999;138:S69-S75.

6 Kharbanda RK, Nielsen TT, Redington AN: Translation of remote ischaemic preconditioning into clinical practice. Lancet 2009; 374:1557-1565.

7 Babiker FA, Joseph S, Juggi JS: What's new in salvage of the ischemic myocardium: estrogen postconditioning. Med Princ Pract 2011;20: 495-496.
8 Murry CE, Jennings RB, Reimer KA: Preconditioning with ischemia: a delay of lethal cell injury in ischemic myocardium. Circulation 1986;74:1124-1136.

9 Ibanez B, Macaya C, Sanchez-Brunete V, et al: Effect of early metoprolol on infarct size in ST-segment-elevation myocardial infarction patients undergoing primary percutaneous coronary intervention: the Effect of Metoprolol in Cardioprotection During an Acute Myocardial Infarction (METOCARD-CNIC) trial. Circulation 2013;128:1495-1503.

10 Zhao ZQ, Corvera JS, Halkos ME, et al: Inhibition of myocardial injury by ischemic postconditioning during reperfusion: comparison with ischemic preconditioning. Am J Physiol Heart Circ Physiol 2003;285:H579-H588.

11 Amit G, Cafri C, Yaroslavtsev S, et al: Intracoronary nitroprusside for the prevention of the no-reflow phenomenon after primary percutaneous coronary intervention in acute myocardial infarction. A randomized, double-blind, placebo-controlled clinical trial. Am Heart J 2006;152:887.

12 Kawai Y, Hisamatsu K, Matsubara H, et al: Intravenous administration of nicorandil immediately before percutaneous coronary intervention can prevent slow coronary flow phenomenon. Eur Heart J 2009;30:765-772.

13 Ovize M, Thibault H, Przyklenk K: Myocardial conditioning: opportunities for clinical translation. Circ Res 2013;113:439-450.
14 Crimi G, Pica S, Raineri C, Bramucci E, et al: Remote ischemic post-conditioning of the lower limb during primary percutaneous coronary intervention safely reduces enzymatic infarct size in anterior myocardial infarction: a randomized controlled trial. JACC Cardiovasc Interv 2013;6:1055-1063.

15 Przyklenk K, Bauer B, Ovize M, et al: Regional ischemic 'preconditioning' protects remote virgin myocardium from subsequent sustained coronary occlusion. Circulation 1993; 87:893-899.

16 Vanagt WY, Cornelussen RN, Poulina QP et al: Pacing-induced dys-synchrony preconditions rabbit myocardium against ischemia/reperfusion injury. Circulation 2006; 114:I264-I269.

17 Vanagt WY, Cornelussen RN, Baynham TC, et al: Pacing-induced dyssynchrony during early reperfusion reduces infarct size. J Am Coll Cardiol 2007;49:1813-1819.

18 Babiker FA, Lorenzen-Schmidt I, Mokelke E, et al: Long-term protection and mechanism of pacing-induced postconditioning in the heart. Basic Res Cardiol 2010;105:523-533.

19 Staat P, Rioufol G, Piot C, et al: Postconditioning the human heart. Circulation 2005; 112:2143-2148.

20 Thibault H, Piot C, Staat P, et al: Long-term benefit of postconditioning. Circulation 2008; 117:1037-1044. 
21 Freixa X, Bellera N, Ortiz-Perez JT, et al: Ischaemic postconditioning revisited: lack of effects on infarct size following primary percutaneous coronary intervention. Eur Heart J 2012;33:103-112.

22 Limalanathan S, Andersen GO, Klow NE, et al: Effect of ischemic postconditioning on infarct size in patients with ST-elevation myocardial infarction treated by primary PCI results of the POSTEMI (POstconditioning in ST-Elevation Myocardial Infarction) randomized trial. J Am Heart Assoc 2014; 3:e000679.

23 Piot C, Croisille P, Staat P, et al: Effect of cyclosporine on reperfusion injury in acute myocardial infarction. N Engl J Med 2008; 359:473-481.

24 Stone GW: Angioplasty strategies in ST-segment-elevation myocardial infarction. II. Intervention after fibrinolytic therapy, integrated treatment recommendations, and future directions. Circulation 2008;118:552-566.

25 Carrasco-Chinchilla F, Munoz-Garcia AJ, Dominguez-Franco A, et al: Remote ischaemic postconditioning: does it protect against ischaemic damage in percutaneous coronary revascularisation? Randomised placebocontrolled clinical trial. Heart 2013;99:14311437.

26 Lavi S, D'Alfonso S, Diamantouros P, et al: Remote ischemic postconditioning during percutaneous coronary interventions: remote ischemic postconditioning-percutaneous coronary intervention randomized trial. Circ Cardiovasc Intervent 2014;7:225-232.

27 Babiker FA, Joseph S, Juggi J: The protective effects of 17beta-estradiol against ischemiareperfusion injury and its effect on pacing postconditioning protection to the heart. J Physiol Biochem 2014;70:151-162.

28 Blaauw E, Lorenzen-Schmidt I, Babiker FA, et al: Stretch-induced upregulation of connective tissue growth factor in rabbit cardiomyocytes. J Cardiovasc Transl Res 2013;6:861-869.

29 Gysembergh A, Margonari H, Loufoua J, et al: Stretch-induced protection shares a common mechanism with ischemic preconditioning in rabbit heart. Am J Physiol 1998;274:H955H964.

30 Granfeldt A, Lefer DJ, Vinten-Johansen J: Protective ischaemia in patients: preconditioning and postconditioning. Cardiovasc Res 2009;83:234-246.

31 Hausenloy DJ, Yellon DM: New directions for protecting the heart against ischaemia-reperfusion injury: targeting the Reperfusion Injury Salvage Kinase (RISK)-pathway. Cardiovasc Res 2004;61:448-460.

32 Babiker FA, van Golde J, Vanagt WY, et al: Pacing postconditioning: impact of pacing algorithm, gender, and diabetes on its myocardial protective effects. J Cardiovasc Transl Res 2012;5:727-734.

33 Kloner RA, Rezkalla SH: Preconditioning, postconditioning and their application to clinical cardiology. Cardiovasc Res 2006;70: 297-307.
34 Hoole SP, Heck PM, Sharples L, et al: Cardiac Remote Ischemic Preconditioning in Coronary Stenting (CRISP Stent) Study: a prospective, randomized control trial. Circulation 2009;119:820-827.

35 Okamura A, Ito H, Iwakura K, et al: Detection and quantification of embolic particles during percutaneous coronary intervention to stable plaque: it correlates to coronary flow dynamics and myocardial damage. Catheter Cardiovasc Interv 2007;69:425-431.

36 Galagudza M, Kurapeev D, Minasian S, et al: Ischemic postconditioning: brief ischemia during reperfusion converts persistent ventricular fibrillation into regular rhythm. Eur J Cardiothorac 2004;25:1006-1010.

37 Wang GY, Wu S, Pei JM, et al: Kappa- but not delta-opioid receptors mediate effects of ischemic preconditioning on both infarct and arrhythmia in rats. Am J Physiol Heart Circ Physiol 2001;280:H384-H391.

38 Birnbaum Y, Hale SL, Kloner RA: Ischemic preconditioning at a distance: reduction of myocardial infarct size by partial reduction of blood supply combined with rapid stimulation of the gastrocnemius muscle in the rabbit. Circulation 1997;96:1641-1646.

39 Hausenloy DJ, Mwamure PK, Venugopal V, et al: Effect of remote ischaemic preconditioning on myocardial injury in patients undergoing coronary artery bypass graft surgery: a randomised controlled trial. Lancet 2007;370:575-579.

40 Venugopal V, Hausenloy DJ, Ludman A, et al: Remote ischaemic preconditioning reduces myocardial injury in patients undergoing cardiac surgery with cold-blood cardioplegia: a randomised controlled trial. Heart 2009;95: 1567-1571.

41 Andreka G, Vertesaljai M, Szantho G, et al: Remote ischaemic postconditioning protects the heart during acute myocardial infarction in pigs. Heart 2007;93:749-752.

42 Kerendi F, Kin H, Halkos ME, et al: Remote postconditioning. Brief renal ischemia and reperfusion applied before coronary artery reperfusion reduces myocardial infarct size via endogenous activation of adenosine receptors. Basic Res Cardiol 2005;100:404-412.

43 Botker HE, Kharbanda R, Schmidt MR, et al: Remote ischaemic conditioning before hospital admission, as a complement to angioplasty, and effect on myocardial salvage in patients with acute myocardial infarction: a randomised trial. Lancet 2010;375:727-734.

44 Taniyama Y, Ito $\mathrm{H}$, Iwakura K, et al: Beneficial effect of intracoronary verapamil on microvascular and myocardial salvage in patients with acute myocardial infarction. J Am Coll Cardiol 1997;30:1193-1199.

45 Villari B, Ambrosio G, Golino P, et al: The effects of calcium channel antagonist treatment and oxygen radical scavenging on infarct size and the no-reflow phenomenon in reperfused hearts. Am Heart J 1993;125:11-23.

46 Ross AM, Gibbons RJ, Stone GW, et al: A randomized, double-blinded, placebo-controlled multicenter trial of adenosine as an adjunct to reperfusion in the treatment of acute myocardial infarction (AMISTAD-II). J Am Coll Cardiol 2005;45:1775-1780.

47 Landoni G, Zangrillo A, Fochi O, et al: Cardiac protection with volatile anesthetics in stenting procedures. J Cardiothorac Vasc Anesth 2008;22:543-547.

48 Alpak G, Ercan S, Alici H, et al: Influence of recurrent electroconvulsive therapy on cardiac function. Med Princ Pract 2014;23:225-228.

49 Rentoukas I, Giannopoulos G, Kaoukis A, et al: Cardioprotective role of remote ischemic periconditioning in primary percutaneous coronary intervention: enhancement by opioid action. JACC Cardiovasc Interv 2010;3: 49-55.

50 Karuppasamy P, Chaubey S, Dew T, et al: Remote intermittent ischemia before coronary artery bypass graft surgery: a strategy to reduce injury and inflammation? Basic Res Cardiol 2011;106:511-519.

51 Pavione MA, Carmona F, de Castro M, et al: Late remote ischemic preconditioning in children undergoing cardiopulmonary bypass: a randomized controlled trial. J Thorac Cardiovasc Surg 2012;144:178-183.

52 Lucchinetti E, Bestmann L, Feng J, et al: Remote ischemic preconditioning applied during isoflurane inhalation provides no benefit to the myocardium of patients undergoing on-pump coronary artery bypass graft surgery: lack of synergy or evidence of antagonism in cardioprotection? Anesthesiology 2012;116:296-310.

53 Rahman IA, Mascaro JG, Steeds RP, et al: Remote ischemic preconditioning in human coronary artery bypass surgery: from promise to disappointment? Circulation 2010; 122:S53-S59.

54 Hong DM, Mint JJ, Kim JH, et al: The effect of remote ischaemic preconditioning on myocardial injury in patients undergoing offpump coronary artery bypass graft surgery. Anaesth Intensive Care 2010;38:924-929.

55 Li L, Luo W, Huang L, et al: Remote perconditioning reduces myocardial injury in adult valve replacement: a randomized controlled trial. J Surg Res 2010;164:e21-e26.

56 Munk K, Andersen NH, Schmidt MR, et al: Remote ischemic conditioning in patients with myocardial infarction treated with primary angioplasty: impact on left ventricular function assessed by comprehensive echocardiography and gated single-photon emission CT. Circ Cardiovasc Imaging 2010;3:656662

57 Bates E, Bode C, Costa M, et al: Intracoronary KAI-9803 as an adjunct to primary percutaneous coronary intervention for acute STsegment elevation myocardial infarction. Circulation 2008;117:886-896.

58 Liem A, van de Woestijne AP, Bruijns E, et al: Effect of EPO administration on myocardial infarct size in patients with non-STE acute coronary syndromes: results from a pilot study. Int J Cardiol 2009;131:285-287. 
59 Desmet W, Bogaert J, Dubois C, et al: Highdose intracoronary adenosine for myocardial salvage in patients with acute ST-segment elevation myocardial infarction. Eur Heart J 2011;32:867-877.

60 Kitakaze M, Asakura M, Kim J, et al: Human atrial natriuretic peptide and nicorandil as adjuncts to reperfusion treatment for acute myocardial infarction (J-WIND): two randomised trials. Lancet 2007;370:1483-1493.

61 Ott I: Tissue factor inhibition: another approach reducing thrombosis after vascular injury. Thromb Haemost 2010;103:7-8.
62 Najjar SS, Rao SV, Melloni C, et al: Intravenous erythropoietin in patients with ST-segment elevation myocardial infarction: REVEAL: a randomized controlled trial. JAMA 2011;305:1863-1872.

63 Fokkema ML, Vlaar PJ, Vogelzang M, et al: Effect of high-dose intracoronary adenosine administration during primary percutaneous coronary intervention in acute myocardial infarction: a randomized controlled trial. Circ Cardiovasc Interv 2009;2:323-329.

64 Ghosh S, Galinanes M: Protection of the human heart with ischemic preconditioning during cardiac surgery: role of cardiopulmonary bypass. J Thorac Cardiovasc Surg 2003; 126:133-142.
$65 \mathrm{Wu}$ ZK, Pehkonen E, Laurikka J, et al: Myocardial lactate production is not involved in the ischemic preconditioning mechanism in coronary artery bypass graft surgery patients. J Cardiothorac Vasc Anesth 2001;15:412417.

66 Cremer J, Steinhoff G, Karck M, et al: Ischemic preconditioning prior to myocardial protection with cold blood cardioplegia in coronary surgery. Eur J Cardiothorac 1997; 12:753-758.

67 Sorensson P, Saleh N, Bouvier F, et al: Effect of postconditioning on infarct size in patients with ST elevation myocardial infarction. Heart 2010;96:1710-1715. 